\title{
Renal cell carcinoma needle biopsy: Sowing the seed for later complications?
}

\author{
Alexander Laird, ${ }^{1}$ Catriona H Couper, ${ }^{1}$ Stephen Glancy, ${ }^{2}$ Marie O'Donnell, ${ }^{3}$ \\ Antony C P Riddick ${ }^{4}$
}

${ }^{1}$ Department of Urology, University of Edinburgh, Edinburgh, UK ${ }^{2}$ Department of Radiology, NHS Lothian, Edinburgh, UK ${ }^{3}$ Department of Pathology, NHS Lothian, Edinburgh, UK ${ }^{4}$ Department of Urology, Addenbrooke's Hospital, Cambridge, UK

\section{Correspondence to} Alexander Laird, alex.laird@ed.ac.uk

Accepted 6 April 2014

\section{SUMMARY}

Pathological examination of a radical nephrectomy for papillary renal cell carcinoma showed tumour present within the perinephric fat, with a morphology indicative of iatrogenic tumour cell tracking caused by previous biopsy of the mass. This is a rare complication of percutaneous biopsy, and as this procedure is becoming more common in investigating renal masses, it is important that the professionals are aware of the potential risks posed by renal mass biopsy.

\section{BACKGROUND}

This case follows a patient's treatment of a malignant renal tumour, the sixth most common cancer in men in the $\mathrm{UK}^{1}$ with an approximate incidence of 19 new kidney cancer cases for every 100000 males in the UK.

Improved CT and ultrasound imaging has led to an increase in the diagnosis of small renal masses (SRMs) and early intervention for malignant disease. These improved modes of imaging allow urologists to propose a management plan without biopsy in many cases, but without histological investigations there is a loss of accuracy in the diagnosis, characterisation and prognostication of localised SRMs with a diameter of less than $4 \mathrm{~cm} .{ }^{2}$ As such, patients with benign disease may potentially be identified as having malignant disease and subjected to unnecessary invasive surgical intervention. As a result, some advocate biopsy in these SRMs to ensure accurate diagnosis before planning invasive management. ${ }^{2-4}$ This prevents unwarranted intervention with associated risk and furthermore may be cost effective. ${ }^{5}$ This is particularly important in older patients with comorbidity, as death from non-cancer-related medical problems is higher than dying from renal cell carcinoma in patients over 66 years old with a high-Charlson comorbidity index score. ${ }^{6}$

Percutaneous biopsy is seen as a safe procedure with complication rates of approximately $14 \% 0^{78}$ most being minor and resolving spontaneously. Seeding following biopsy of renal tumours is rare, often cited as being less than $0.01 \% .^{9}$ We report the third reported case of seeding of a papillary renal cell carcinoma (PRCC) following biopsy.

\section{CASE PRESENTATION}

A 58-year-old man presented with abdominal pain and an ultrasound was performed for suspected gallstones.

\section{INVESTIGATIONS}

The ultrasound did not show any hepatobiliary abnormalities, but a $24 \mathrm{~mm}$ exophytic lesion with calcification in the left kidney was found incidentally. An abdominal CT scan confirmed a left lateral lower pole renal lesion (figure 1). This was compared with a previous T1-weighted sequence from a prostate MRI from 2011 (for symptomatic prostatitis) where a lesion of similar size was found in the same location.

The patient's case was discussed at the urology multidisciplinary meeting (MDM) with the differential diagnoses of oncocytoma and renal cell carcinoma made. As these two pathologies have different initial management (former can be managed non-surgically with follow-up in the majority of cases ${ }^{10}$ ), biopsy was recommended. The patient agreed and underwent ultrasound-guided biopsy of the lesion (figure 2), which proved challenging. An 18G biopsy needle was used without coaxial introducer to take five samples of the lesion. There were no immediate complications.

Microscopic examination of the biopsies showed features typical of a type 1 PRCC.

\section{TREATMENT}

After further discussion at the MDM, surgical resection was recommended, with either partial or radical nephrectomy. After discussing these treatment options with the patient, he underwent laparoscopic radical nephrectomy without complication 2 months after the initial biopsy.

\section{OUTCOME AND FOLLOW-UP \\ Pathology}

Macroscopic examination of the radical nephrectomy specimen revealed a $28 \mathrm{~mm}$ solid cream mass



Figure 1 Coronal section of the CT image demonstrating renal mass in the left kidney (labelled A). 




Figure 2 (A) Ultrasound image demonstrating left renal mass. (B) Annotated image demonstrating ultrasound probe location, subcutaneous and perinephric fat (i), renal mass (ii) and left kidney (iii).

in the lower lateral aspect of the kidney. The tumour was well circumscribed and there was no macroscopic invasion of the perinephric fat, sinus fat, pelvicalyceal system or renal vein. There was a second similar circumscribed cream lesion present in the upper pole of the kidney, measuring $8 \mathrm{~mm}$ in diameter and a third lesion $3 \mathrm{~mm}$ in diameter just over $45 \mathrm{~mm}$ from the main lesion.

Histological sections confirmed that the main tumour was a type 1 PRCC. It showed the typical tubulopapillary architecture with low-grade nuclear cytology and prominent areas of necrosis, foamy macrophage infiltration and calcification (figure 3). The second lesion seen in the upper pole of the kidney was a further small type 1 PRCC showing prominent calcification. The $3 \mathrm{~mm}$ lesion identified macroscopically was a benign papillary adenoma. The main tumour was well circumscribed with a very clear boundary formed by the intact renal capsule separating it from the surrounding perinephric fat. However, lying within the perinephric fat adjacent to the underlying tumour were several discohesive foci of similar appearing tumour cells. On deeper sectioning, these joined together to form a linear track, within which there were foci of tumour surrounded by a desmoplastic reaction (figure 4). On higher power, the tumour groups were also associated with an inflammatory reaction, including haemosiderin-laden macrophages and significant aggregates of foreign body giant cells within which there was non-refractile foreign material (figure 5). The appearances were indicative of seeding of the previous core biopsy track. The foci were well clear of the surrounding circumferential resection margin.

\section{Outcome and follow-up}

The patient was discharged on day 2 following nephrectomy without complication. He was reviewed 2 weeks postoperatively

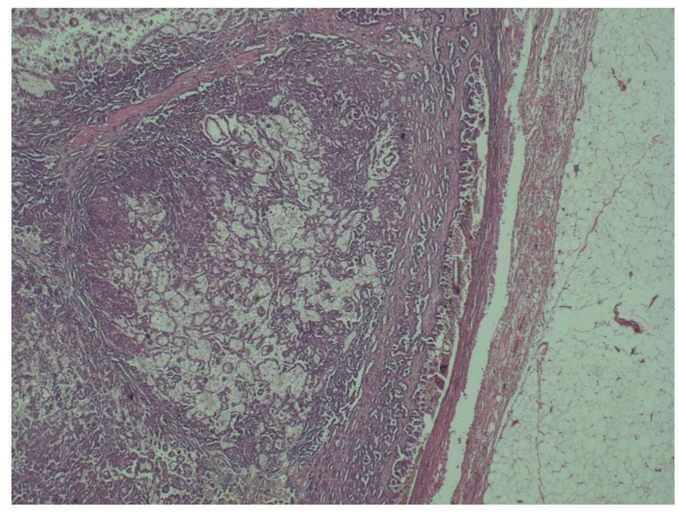

Figure 3 Low-power magnification of the neoplasm showing features characteristic of a type 1 papillary carcinoma of the kidney.

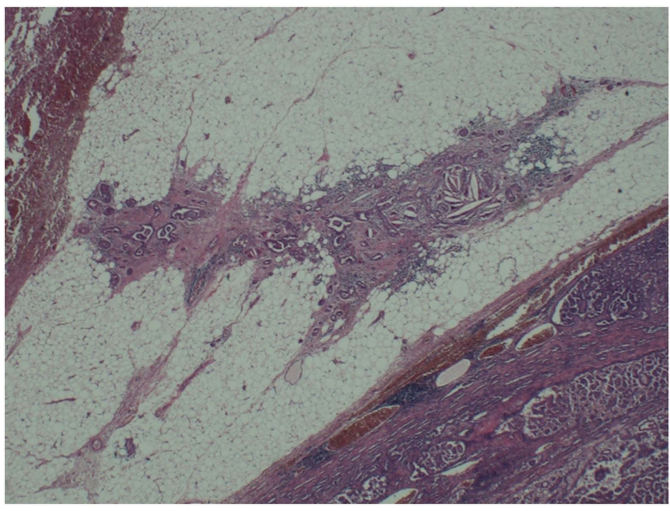

Figure 4 Low-power magnification of core biopsy track seeded by papillary carcinoma set in a fibrous stroma in the perinephric fat adjacent to the renal neoplasm.

to discuss pathology results. One year following nephrectomy the patient is well. Follow-up CT of his abdomen and pelvis was unremarkable with no disease recurrence. Follow-up will be annually as per our standard protocol for pT1 tumours.

\section{DISCUSSION}

Tumour size is linked to malignant potential in renal tumours. This patient's risk of renal cell carcinoma based on tumour size on CT was $78 \% .^{11}$ This level of risk is deduced from analysis of 2935 renal masses at time of resection. ${ }^{11}$ Similarly, a separate histological study of resected renal masses in populations similar to our patient (for age, sex and tumour size) has found 15.9\% of patients to have benign disease on histology. Some of these patients may avoid surgery and be managed on a surveillance programme. $^{12}$

Many patients with SRMs potentially benefit from having a biopsy prior to surgery thereby guiding their treatment. However, a significant number of urologists are still reluctant to use a renal biopsy in the management of the patient with the SRM, as indicated by a recent survey at the World Congress of Endourology. The survey found that $55.9 \%$ of urologists surveyed would never obtain a preoperative biopsy, ${ }^{13}$ despite potentially saving patients from the harm of undergoing surgery, and reducing burden on surgical services.

Lack of confidence in the role of renal mass biopsy is due to historical reports of high false-negative rates, and due to the



Figure 5 Higher power view of core biopsy track seeded by papillary carcinoma and including an inflammatory reaction including cholesterol clefts containing giant cells. 
belief that a biopsy would not alter patient management. ${ }^{14}$ However, advances in biopsy and histopathological techniques have resulted in a diagnostic accuracy of $>90 \%$ of cases reported by some series. ${ }^{15}$ While the benefit of biopsy in selected groups, such as the elderly and comorbid, can be clearly seen, it could be argued that all SRMs with diagnostic uncertainty should be biopsied. Furthermore, with research in the realms of prognostic and predictive biomarkers in progress the increased use of renal biopsy could be anticipated.

In this case the decision to biopsy the renal mass was in keeping with the guidelines in Europe and America. ${ }^{16} 17$ The discovery that tumour cells had seeded into the perinephric fat during the biopsy procedure was most unexpected. The risks of such an occurrence seem almost negligible in the guidelines offered to urologists. While we accept the risk is extremely low, the consequences of tumour tracking may be significant for the affected patient. Like the most recent reported incident of PRCC tracking along a biopsy core, ${ }^{18}$ a coaxial technique was not used in this case because of difficulty in visualising the lesion on the ultrasound. Furthermore, as is often the case, the needle was also difficult to visualise, particularly in the subcutaneous fat. In these difficult cases we believe the use of a standard biopsy needle allows greater freedom of manipulation and a resultant greater success of diagnostic biopsy. While CT-guided biopsy could be advocated when visualisation is difficult with ultrasound, this resource is often limited in availability and realtime assessment of needle position is more difficult. A coaxial technique is recommended to reduce tumour seeding; however with increased biopsies we may expect to encounter more of these difficult clinical situations requiring an alternative biopsy technique.

PRCC accounts of up to $10 \%$ of malignant renal cell carcinomas in adults. There are two distinct types. The more common, type 1 PRCC, as found in this case, is less prone to metastasising and has a lower malignant potential compared with the more common clear-cell variant of renal cell carcinoma. What yet remains to be determined is whether particular subtypes of renal cell carcinoma might have a higher propensity for seeding of the needle core track. It is interesting to speculate on this given that

\section{Learning points}

- Percutaneous biopsy of renal masses detected with imaging should precede operative management or ablative therapy where the lesion is not clearly suspicious since it can influence management, particularly if the mass is small.

- European guidelines recommend tumour biopsy using a coaxial technique to avoid tumour seeding - in this case a coaxial technique was not used due to the difficulty in obtaining a biopsy. We may expect to encounter greater numbers of these hard-to-biopsy lesions, and subsequently deviations from the coaxial technique may also become more common in order to gain a tissue biopsy. The potential of seeding should be remembered in such cases.

- Pathologists need to be aware of the possibility of seeding of perinephric fat following previous biopsy to prevent interpretation of the changes as true perinephric fat invasion and consequent pathological upstaging of the tumour.

- With increased biopsying of renal masses, we should be prepared to see some unusual consequences of this procedure such as tumour-cell seeding along core biopsy tracts. this is the third case report of seeding of a core biopsy track in PRCC. This could have implications for further management choices, particularly where limited surgery or ablative therapies are being considered. Awareness of the potential for seeding of the needle biopsy tract is also of importance for the reporting pathologist. Misinterpretation of the presence of tumour in perinephric fat as genuine invasion could lead to the carcinoma being significantly upstaged and may lead to unnecessary concern regarding future prognosis. The presence of giant cells in association with the focus, together with the relatively linear orientation of the perinephric deposit in a patient with a history of renal mass biopsy should lead to correct diagnosis.

We should seek to ensure that those clinicians providing investigative procedures of renal masses, and their patients, are aware of this rare complication. It is possible that seeding will become more prevalent with increased biopsy of renal tumours. Increased awareness will allow us to determine whether it has any negative impact on patient outcome.

Contributors $\mathrm{AL}$ and ACPR were involved in the conception and design of the manuscript. AL, CHC, SG and MOD were involved in the acquisition and interpretation of data. AL, CHC, SG and MOD drafted the article and ACPR was involved in revising it critically for important intellectual content. All authors gave final approval of the version published.

\section{Competing interests None.}

\section{Patient consent Obtained.}

Provenance and peer review Not commissioned; externally peer reviewed.

\section{REFERENCES}

1 Cancer Research UK. Kidney cancer incidence statistics. 2012. http://www. cancerresearchuk.org/cancer-info/cancerstats/types/kidney/incidence/uk-kidneycancer-incidence-statistics

2 Gautam G, Zorn K C. The current role of renal biopsy in the management of localized renal tumors. Indian J Urol 2009;25:494.

3 Volpe A, Mattar K, Finelli A, et al. Contemporary results of percutaneous biopsy of 100 small renal masses: a single center experience. J Urol 2008;180:2333.

4 Volpe A, Kachura JR, Geddie WR, et al. Techniques, safety and accuracy of sampling of renal tumors by fine needle aspiration and core biopsy. J Urol 2007;178:379.

5 Pandharipande PV, Gervais DA, Hartman RI, et al. Renal mass biopsy to guide treatment decisions for small incidental renal tumors: a cost-effectiveness analysis. Radiology 2010;256:836

6 Kutikov A, Egleston BL, Canter D, et al. Competing risks of death in patients with localized renal cell carcinoma: a comorbidity based model. J Urol 2012;188:2077.

7 Hergesell O, Felten $\mathrm{H}$, Andrassy $\mathrm{K}$, et al. Safety of ultrasound-guided percutaneous renal biopsy-retrospective analysis of 1090 consecutive cases. Nephrol Dial Transplant 1998;13:975.

8 Whittier WL, Korbet SM. Timing of complications in percutaneous renal biopsy. J Am Soc Nephrol 2004;15:142

9 Smith EH. Complications of percutaneous abdominal fine-needle biopsy review. Radiology 1991;78:253.

10 Neuzillet $Y$, Lechevallier $E$, Andre $M$, et al. Follow-up of renal oncocytoma diagnosed by percutaneous tumor biopsy. Urology 2005;66:1181.

11 Frank I, Blute ML, Cheville JC, et al. Solid renal tumors: an analysis of pathological features related to tumor size. J Urol 2003;170:2217.

12 Neuzillet $Y$, Lechevallier $E$, Andre $M$, et al. Accuracy and clinical role of fine needle percutaneous biopsy with computerized tomography guidance of small (less than $4.0 \mathrm{~cm}$ ) renal masses. J Urol 2004;171:1802.

13 Kummerlin IP, Borrego J, Wink MH, et al. Nephron-sparing surgery and percutaneous biopsies in renal-cell carcinoma: a global impression among endourologists. J Endourol 2007;21:709.

14 Khan AA, Shergill IS, Quereshi S, et al. Percutaneous needle biopsy for indeterminate renal masses: a national survey of UK consultant urologists. BMC Urol 2007;7:10.

15 Wang R, Wolf JS Jr, Wood DP Jr, et al. Accuracy of percutaneous core biopsy in management of small renal masses. Urology 2009;73:586.

16 Ljungberg B, Bensalah K, Bex A, et al. Guidelines on Renal Cell Carcinoma. European Association of Urology, 2014. http://www.uroweb.org/gls/pdf/10\% 20Renal\%20Cell\%20Carcinoma_LR.pdf

17 Novick AC, Campbell SC, Belldegrun A, et al. AUA Guideline for Management of the Clinical Stage 1 Renal Mass, 2009;182:1271-9.

18 Mullins JK, Rodriguez R. Renal cell carcinoma seeding of a percutaneous biopsy tract. Can Urol Assoc J 2013;7:E176. 
Copyright 2014 BMJ Publishing Group. All rights reserved. For permission to reuse any of this content visit http://group.bmj.com/group/rights-licensing/permissions.

BMJ Case Report Fellows may re-use this article for personal use and teaching without any further permission.

Become a Fellow of BMJ Case Reports today and you can:

- Submit as many cases as you like

- Enjoy fast sympathetic peer review and rapid publication of accepted articles

- Access all the published articles

- Re-use any of the published material for personal use and teaching without further permission

For information on Institutional Fellowships contact consortiasales@bmjgroup.com

Visit casereports.bmj.com for more articles like this and to become a Fellow 